\title{
POSITIVE EXTERNALITIES OF EU ACTIONS ON SUSTAINABILITY OF HEALTH SYSTEMS*
}

\author{
Sophie Guthmuller, ${ }^{1,2}$ Paolo Paruolo, ${ }^{1}$ \\ and Stefano Verzillo ${ }^{1}$
}

\begin{abstract}
This chapter summarises the role of EU actions in supporting healthcare policies in the EU Member States, both looking at implemented actions and describing current priorities for the future. It argues that these coordinated actions can be beneficial for EU Member States by helping them to avoid duplication of effort and to attain economies of scale. Moreover, data sharing with proper safeguards can unleash vast amount of 'learning what works' both
\end{abstract}

\footnotetext{
${ }^{*}$ The views set out in this paper are those of the authors and do not necessarily reflect the ones of the institutions of affiliation. All authors have equally contributed to the preparation of the manuscript. The authors acknowledge useful comments on a previous version of the chapter from Benedetta Martinelli, Santiago Alvaro Calvo Ramos, Ciarán Nicholl, Sandra Caldeira, Manola Bettio, Annett Roi Januch, the Editors and a Referee. This research was conducted while Sophie Guthmuller was in service at the European Commission's Joint Research Centre. The final revisions of the text of the chapter have been conducted when Sophie Guthmuller took service at the Health Economics and Policy Group of Vienna University of Economics and Business. Correspondence to Sophie Guhmuller.

${ }^{1}$ European Commission, Joint Research Centre, Ispra, Italy.

${ }^{2}$ Health Economics and Policy Group, Vienna University of Economics and Business, Austria and RWI Research Network, RWI Essen, Germany.
}

The Sustainability of Health Care Systems in Europe

Contributions to Economic Analysis, Volume 295, 1-21

Chapter 1, Positive externalities of EU actions on sustainability of Health Systems is Open Access. (C) 2021, Sophie Guthmuller, Paolo Paruolo, Stefano Verzillo. Published by Emerald Publishing Limited. This work is published under the Creative Commons Attribution (CC BY 4.0) licence. Anyone may reproduce, distribute, translate and create derivative works of these works (for both commercial and non-commercial purposes), subject to full attribution to the original publication and authors. The full terms of this licence may be seen at http://creativecommons.org/ licences/by/4.0/legalcode

ISSN: 0573-8555/doi:10.1108/S0573-855520210000295006 
for medical treatments and for healthcare sustainability measures. The need for this common learning appears ever more urgent while facing the health and economic consequences of the present pandemic.

Keywords: Health policy; Europe; sustainability; health system; evidence-based policy; what works

JEL classification: I18

\section{INTRODUCTION}

Over the last 15 years, European Union (EU) health systems have faced growing common challenges: an increasing cost of healthcare, the ageing of population, a rise of chronic diseases and multi-morbidity leading to growing demand for healthcare, the shortage of health professionals, growing health inequalities and inequity in access to healthcare. These challenges are exacerbated by recent economic crises, including the financial crisis of 2008 and the one created by the containment measures for the COVID-19 pandemic, which impact the ability of EU Member States to finance healthcare.

Common shocks and growing interdependence require closer coordination in the EU. Member States are responsible for the national health systems and their financing. The role of the EU mainly follows from the subsidiarity principle, which foresees that EU actions are undertaken if they are expected to be more effective than actions taken at national, regional or local level. This is linked with the principle of proportionality, which states that EU actions should not exceed what is strictly necessary for the objectives of the Treaties. ${ }^{1}$

Sustainability of the health system, from the fiscal, financing, and access angles is important in ensuring the fundamental health rights of EU citizens. ${ }^{2}$ It is also important to address social consequences of economic crises, because people's health is influenced by them and it influences economic outcomes in terms of productivity, labour supply, human capital, with a feedback loop to public spending and hence to the financing of health systems.

The EU has a large policy portfolio, which includes both regulation and guidance and spending programmes, with expected impacts on the environment, social outcomes, consumer protection and the Internal Market. These interventions have often indirect impact on health outcomes. Moreover, the EU also takes direct actions. This chapter aims to:

- describe the broad areas of actions of the EU and its structural functioning;

- summarise implemented EU interventions and available evidence on sustainability;

- introduce challenges for EU Health Policy and the current outlook on them, including how to better prepare for health emergencies (learning from the actual COVID-19 pandemic) and how to improve the sustainability of healthcare systems.

The chapter also observes that sharing data and evidence of 'what works' is one additional channel to generate positive externalities of EU actions, in view of increasing the efficiency and the long-term sustainability of healthcare systems. 
The current COVID-19 pandemic is putting public health policy on top of public agenda (media, politics, society), and it is making clear that more coordination, cooperation and common learning among EU health systems is more necessary than ever. Learning what works appears central for 'evidence-informed policy making', see e.g., Crato and Paruolo (2019) for a recent exposition.

The rest of the chapter is organised as follows. Section 2 summarises the role of EU actions to improve sustainable health systems. Section 3 describes past EU actions and selected available evidence, while Section 4 looks forward to how current priorities can generate positive externalities for EU Member States. Section 5 concludes.

\section{ROLE AND ACTIONS OF THE EUROPEAN UNION}

The role of the EU in Health is to improve healthcare and the health status of its citizens by fostering collaboration among Member States, health promotion activities and financial support.

\section{Legal Background}

The EU role in Public Health and Social Policy is a competence shared with EU Member States, as defined under Article 168 and Article 153 of the Treaty on the Functioning of the European Union. While Member States define and deliver their national health services and medical care, the EU seeks to complement national policies to ensure health protection in all EU policies, with the definition of Community health strategies following the subsidiarity and proportionality principles.

Community public health objectives were first defined in 1993, after the ratification of the Maastricht Treaty in 1992 (Article 129) including programmes on cancer, on AIDS and on combating drug dependence; this included a mandate to report on the state of health in the EU and to provide recommendations on blood safety. From 2002, public health objectives are revised and integrated into a common Health Strategy (European Parliament and Council, 2002).

Today, a health perspective is included in all EU policies; this is viewed as an investment to achieve sustainable and inclusive growth. The health sector in Europe falls under the rules set by the Internal Market (Single European Act, 1986) in which the freedom of movement of goods, services, people and capital is ensured. The different freedoms of movement imply that the EU may affect national health systems through harmonised regulation concerning goods, services, and people in the health sector. Examples include pharmaceuticals, medical devices, pharmacy, the health workforce, e-health, social security coordination, and cross-border healthcare and patient mobility across EU Member States.

European healthcare systems, and in particular healthcare expenditures in EU Member States, are also affected by rules on the Internal Capital Market and by the EU objective of fiscal sustainability, the so-called Stability and Growth Pact. ${ }^{3}$

\section{Health Strategy}

The EU has defined principles and strategic issues within a common Health Strategy since 2002. These principles and strategic themes are regularly revised to 
address common health challenges faced by EU Member States. A 'New Health Strategy' was defined in 2007 (European Commission, 2007). This provided a strategic framework including core issues in (global) health and introduced a health perspective in all EU policies for the first time. It defined three main objectives: (1) to foster good health in an ageing Europe, (2) to protect EU citizens from health threats and (3) to support new technologies and EU Member States' healthcare systems.

For these objectives, the EU gave key statements on health system values and sustainability. In 2006, the Council of Health Ministers agreed on common health system values of universality, access to good quality care, equity, and solidarity. These common values are also in accordance with the principles and rights declared in the European Pillar of Social Rights in 2017 (European Pillar of Social Rights, 2017), and confirm healthcare as a common European priority.

The supportive role of the EU on the sustainability of health systems in EU Member States, which comprises both the elements of fiscal sustainability and healthcare access, has been reinforced since 2006 by the Health Ministers with several Council conclusions (European Council 2006, 2011, 2013). This led to the definition of a specific EU agenda on health systems in 2014 (European Commission, 2014), with a focus on (1) strengthening the effectiveness of health systems, (2) increasing the accessibility of healthcare and (3) improving the resilience of health systems.

Sustainability of health systems can be viewed as a strategic action - within a broad and integrated approach - to ensure the overall resilience or long-term sustainability of a health system, especially in times of economic and pandemic crises. A 'resilient health system is one which is able to effectively prepare for, withstand the stress of, and respond to the public health consequences of disasters' (Bayntun, 2012; Kruk, Myers, Varpilah, \& Dahn, 2015). In this context, coordinated actions have been agreed at EU level on patient safety and quality of care, integration of care and the creation of an Expert Group on Health Systems Performance Assessment.

Accessibility of healthcare includes several components: availability of the health workforce, cost-effective use of medicines (access to affordable and effective medicines), health technology assessment (HTA) and access to healthcare in any EU Member State (Directive 2011/24/EU, European Parliament and Council, 2011). Finally, common actions on the use of health informations and e-health have been agreed to foster resilient health systems (European Commission, 2018c). These coordinated actions are further discussed in the next section.

\section{Policy Instruments}

A range of instruments exist that aim to operationalise and deliver on the Health Strategy and the EU objectives on healthcare systems. These instruments include funding, such as the Health Programme (HP), the Structural Investment Funds, the Research and Innovation framework programmes (FPs). Other instruments are of guidance type, such as the European Semester. These instruments are briefly reviewed in the following subsections. 


\section{Health Programme}

The HP is the main funding instrument since 2002. It supports the Health Strategy, the cooperation among EU Member States and it develops EU health activities. Agreed for a period of seven years, three HPs have been funded so far, with the fourth one about to be launched. To deliver on the priorities or main objectives set in each HP, funds are allocated through project and operating grants, joint actions and conference grants, direct grants to international organisations, and procurements and other actions.

The first HP covered the period 2003-2007, and it allocated $€ 312$ million to the achievement of three main objectives: to improve information and knowledge for the development of public health, to enhance the capability of responding rapidly and in a coordinated fashion to threats to health; and to promote health and prevent disease through addressing health determinants across all policies and activities (European Parliament and Council, 2002).

The second HP (2008-2013), set 'reducing health inequalities' as one of the main objectives, in addition to the promotion of health, the generation and dissemination of health information, and the improvement of citizens' health security. The budget allocated to the second HP was $€ 321.5$ million (European Parliament and Council, 2007).

The third HP (2014-2020), with a budget of $€ 449.4$ million, aims to promote 'innovative, efficient and sustainable health systems' and 'facilitate access to high quality, safe healthcare for EU citizens'. Two other objectives remain the promotion of health - prevent disease and foster healthy lifestyles through 'health in all policies' - and the protection of EU citizens from serious cross-border health threats (European Parliament and Council, 2014).

The outlook on the future fourth HP is reviewed in Section 4.

\section{Structural Funds}

The European Fund for Strategic Investments provides funding for a number of investment priority areas in the health sector, such as investments in new health solutions, medicines and social infrastructures (European Parliament and Council, 2015). In particular, the health sector receives funding from the European Regional Development Fund (ERDF) and the European Social Fund (ESF).

ERDF supports investment in health infrastructure and equipment, e-health, research and support to small- and medium-sized enterprises, while ESF finances health activities aiming at the promotion of health, such as reducing health inequalities, or supporting the health workforce. ERDF and ESF projects on health amount approximately to $€ 5$ billion in 2007-2013 and $€ 9$ billion in 2014-2020 (Watson, 2016).

\section{Research and Innovation}

Health challenges faced by EU countries are also supported by Research and Innovation Framework Programmes (FPs). Spanning seven year, the first FP (FP1) was adopted in 1983. Eight FP programmes haven been funded so far (FP1-FP7, Horizon 2020). 
The range of topics covered and the budget allocated to the programme have evolved over time. The proportion of the EU budget dedicated to research was below $2 \%$ before FP1 and it is currently $7.5 \%$. The funding allocated to health and biotechnologies has increased from one FP to the next, and it represents the thematic area with overall third highest cumulative budget (more than $€ 20$ billion), after ICT ( $€ 35$ billion) and energy (nuclear and non-nuclear, around $€ 30$ billion), see Reillon (2015). The Horizon 2020 FP dedicated section on health covers topics on health, demographic change and well-being.

\section{European Semester}

A different type of policy instrument is provided by the European Semester. This is a core component of the Economic and Monetary Union; it annually aggregates different processes of control, surveillance and coordination of budgetary, fiscal, economic and social policies. It formulates Country-Specific Recommendations (CSR), which cover anything that might affect the Stability and Growth Pact compliance and macroeconomic imbalances, including the fiscal sustainability of health systems. In the recent years, health has become an increasing important topic among socio-economic policies within the third pillar of the European Semester ${ }^{4}$ (Greer et al., 2019).

The European Semester considers several aspects of healthcare system and provides national recommendations on these aspects. The first aspect is that of fiscal sustainability, in accordance with monitoring compliance with the Stability and Growth Pact. In accordance with the Horizontal Assessment Framework (European Commission, 2013) it focuses on countries where fiscal sustainability problems may arise in the medium or long-term, discussing areas where relative inefficiencies are likely to be present.

A more qualitative country-specific analysis is performed for those Member States which are in line with the principles discussed in the Joint Report on Healthcare and Long-term care systems (European Commission, 2016b); the results are published in the annual Country Reports which form the evidence base for subsequent CSRs.

In parallel, an assessment is made on the accessibility and quality of care of each Member State. As is the case for fiscal sustainability, the relevant issues are discussed with the authorities, academic experts and stakeholders. The analysis for those countries which are assessed to have particularly relevant shortcomings in this area is published in the Country Reports.

In association with the European Semester, a new Structural Reform Support Programme and Service has been recently established, with the purpose to provide tailor-made support to EU Member States for reforms in various areas, including healthcare and long-term care systems. In 2020, the Service has become the new Directorate General for Reform of the Commission.

\section{EVIDENCE ON SELECTED EU ACTIONS}

This section describes selected EU actions implemented in the past, together with the available evidence on their effectiveness. 


\section{Fighting Cancer}

One of the main challenges for achieving healthcare systems that are both accessible and fiscally sustainable is posed by cancer-related diseases. Unprecedented demographic and environmental changes throughout the EU will likely and substantially increase the incidence of cancer over the next few decades, probably putting Member States' national systems and their economic and fiscal sustainability to the test.

Cancer is actually the second cause of death in Europe (1.3 million in 2016, about $26 \%$ of the total deaths) being responsible of a large burden on EU health and social systems; this has an impact on Member States' budgets, it impairs growth and productivity.

The total societal cost of cancer has been recently estimated to be close to $€ 199$ billion in 2018 (Hofmarcher, Lindgren, Wilking, \& Jönsson, 2020), ${ }^{5}$ $€ 103$ billion of which refers to direct healthcare costs (treatment, medications and drugs), $€ 26$ billion to informal care while $€ 70$ billion accounts for indirect effects such as negative effects on labour market outcomes for EU citizens (including reduction in productivity because of premature deaths and morbidities).

For these reasons, the EU and national governments have been devoting particular attention to the 'fight against cancer' in the last two decades. In particular, actions promoted at EU level to fight cancer have been mainly aimed at (1) providing a framework of cooperation between national cancer bodies, (2) promoting research and developments, (3) circulating best practices on prevention and treatment and (4) regulating the market of cancer-related pharmaceutical substances since 2002 when the EC adopted the first HP.

In addition, the European Semester has also played a role in this context, issuing CSRs for several countries with the recommendation to spend more on prevention and health promotion, which has the potential to reduce the number of people who develop cancer. Moreover, these CSRs suggested to promote the rational use of pharmaceuticals, ensuring effective negotiation of prices, HTA analysis of new medicines and use of generics where and when appropriate.

\section{Harmonisation of Cancer Screening}

The European Union has limited leverage regarding cancer treatment in Member States; however, it has a primary role in the implementation and harmonisation of cancer screening programmes and in fostering citizens' responsibility. ${ }^{6}$

It is estimated that at least one third of all cancer cases could be prevented and prevention remains the most effective long-term strategy to reduce cancer-related expenditure for Member States. The Council Recommendation 327/36 of 2003 promoted the implementation of population-based quality-assured screening programmes for breast, cervical and colorectal cancer in all Member States over a four-year period (Council, 2003).

With the European Partnership for Action Against Cancer - introduced in 2009 - the adoption of National Cancer Control Programmes helped in achieving a substantial improvement in the number of cancer screening programmes in the 
EU, with more than 500 million screenings performed between 2010 and 2020. As of today, almost all Member States have already adopted such programmes.

In this context, quasi-experimental evidences showed how the implementation of local breast cancer screening programmes increases mammography uptakes by around $24 \%$, while experimental evidence showed how mammography reduces breast cancer mortality in women over age 50 by $25 \%-30 \%$ (Schopper \& Wolf, 2009; \& Carrieri \& Wübker, 2016), extending patients life and reducing subsequent cancer-related healthcare expenditures.

Achieving significant results in the fight against cancer is not only a matter of screening implementation only. In fact, a lack in planning experience combined with limited management capacities in Member States may result in low quality screening programmes that use relatively large amounts of resources without significant benefits. This calls for an EU effort towards the harmonisation of cancer screening programmes in Member States along with the publication of dedicated guidelines to ensure the delivery of high-quality screening procedures.

The second HP started a specific Joint Action called 'European Guide for Quality National Cancer Control Programmes', providing an outline for policymakers on the basic principles of cancer control policies. The publication of a dedicated guideline for developing national cancer plans in all Member States was one of the relevant results obtained by this programme.

To this end, a relevant example is the EC Initiative on Breast Cancer ${ }^{7}$ coordinated by DG JRC and DG SANTE which develops guidelines for breast cancer screening and diagnosis (European Breast Guidelines) and a quality assurance scheme to promote an efficient use of resources and facilitate implementation in all Member States. In addition, a new EC Initiative on Colorectal Cancer ${ }^{8}$ is about to be launched. Colorectal cancer is the second cause of death from cancer in EU with 173,233 associated deaths in 2018 (as reported by the European Cancer Information System). The EC Initiative will develop evidence-based guidelines and a quality assurance scheme for healthcare services involved in the colorectal cancer care pathway.

In addition, activities under a second HP's Joint Action also led to the development of European Networks in cancer care with the aim of efficiently help patients at regional, national and EU levels. The second HP also made a proposal which led to the development of the new European Cancer Information System. ${ }^{9}$

This information system, developed and maintained by the European Commission's Joint Research Centre and launched in February 2018, is a comprehensive health and research data infrastructure harmonising information provided by national cancer registries with the aim of obtaining robust information useful to facilitate the description and interpretation of the evolution of cancer in the European Union. It provides and allows to visualise information on cancer burden indicators across European areas, building on a framework for interoperability of all European cancer registries as data providers. It actually collects more than 34 million cancer records provided by approximately 150 European population-based cancer registries from 34 European countries.

Moreover, an EU effort in the direction of fighting cancer is central also in the ongoing third HP, ${ }^{10}$ which explicitly aims at preventing chronic diseases 
including cancer, age-related diseases and neurodegenerative diseases (Thematic Objective 1.4) with a budget of $€ 17.2$ billion to be spent by 2020 (over a total budget of $€ 49.4$ million).

\section{Fighting Cancer via Research}

A particularly relevant EU action to fight cancer and help Member States to support their healthcare systems is through investment in research. Cancer research is still fragmented, but several collaborations within the EU framework have been encouraged via the Seventh Framework Programme and Horizon 2020 funding programs. The European Union has funded around 1,800 cancer-related projects in the last 20 years with an EU budget of around $€ 3$ billion.

Output of this cancer-related projects accounts for over 4,000 scientific publications, more than 150 patents, support to about 1,000 SMEs in the healthcare sector and support of clinical research with more than 10,000 patients treated in over 120 clinical trails. Cancer research in the European Union is reported by the Organisation of European Cancer Institutes ${ }^{11}$ to be able to produce relevant and valuable results enabling the implementation of new treatment and diagnostic methods, with a potential to improve the life of the patients (Ringborg, Pierotti, Guy, \& Tursz, 2008).

\section{EU Actions through the Internal Market}

Healthcare expenditure shows large variations among EU Member States, both its level and in growth rates, as reported by OECD \& European Union (2018).

In the last two decades, the per-capita health expenditure experienced a period of stability (or even decline in some Member States) after the great recession of 2008 , followed by a positive upward trend in the most recent years. The yearly growth rate of health expenditure per-capita went from $0.6 \%$ in the period 2009 2013 to $1.9 \%$ between 2013 and 2017. The total healthcare expenditure in the EU is close - on average - to $9.6 \%$ of EU GDP, with France (11.5\%) and Germany $(11.3 \%)$ having the highest shares of GDP spent on health, and Romania $(5.2 \%)$, Latvia and Lithuania (both at 6.3\%) the lowest.

In this context, rationalising healthcare expenditures without lowering quality of service and improving efficiency appears important to ensure sustainability of the EU healthcare systems; this, in turn, would protect the ability of Member States to ensure unhindered access to healthcare to its citizens.

\section{Pharmaceuticals and Medical Devices}

The EU Internal Market regulatory framework foresees actions aiming to increase the efficiency of healthcare expenditures at EU level beyond the CSRs and the European Semester. This regulation applies - among others - to pharmaceuticals, medical devices, cross-border healthcare (Legido-Quigley, Glinos, Baeten, McKee, \& Busse, 2012) and HTA. In all respects, health-related goods are considered as a relevant part of the EU Internal Market. 
In particular, the HTA may be a relevant instrument for the evaluation of pharmaceuticals and new medical devices in terms of both their clinical value and cost-effectiveness.

In fact, recent research highlights a large heterogeneity in the EU in the use of economic evaluation to support decisions regarding reimbursement of new health technologies and the assessment of their cost-effectiveness. While in northern Europe (including the United Kingdom), this has long been the standard approach, it has been less common in central and southern Member States, where benefits are more often assessed only in terms of their clinical added value. Hence, there is still room for increasing the use of economic evaluation of pharmaceuticals and new medical technologies in many EU Member States, see Tarricone, Torbica, and Drummond (2017), and to help increase efficiency in spending, see European Commission (2016b, 2017).

A second challenge is given by the increase in pharmaceutical prices. In fact, after inpatient and outpatient care, pharmaceuticals make the third largest healthcare expenditure item, close to $15 \%$ of the overall health expenditure in the EU. The rise in pharmaceutical market competition with the introduction of generic medicines can play a role in sustaining patient access to healthcare and affordability for the public payer (Directive 2001/83/EC). In general, variations in medicine prices and market shares between Member States may be attributed to national differences in pricing and reimbursement regulations, in prescribing policies and in generic substitution laws (Wouters, Kanavos, \& McKee, 2017).

As for generic drugs, recent literature shows how the average prices of pharmaceutical products in the EU has fallen by approximately $20 \%$ in the first year after the expiration of the drug's patent, with a further $5 \%$ drop over the next two years (European Commission, 2009).

However, delays for a generic product to enter the market after the expiration of a patent still exist; these delays have been estimated to cost yearly around $€ 3.4$ billion, based on retail prices (European Commission, 2009). Recent literature has also found that these delays seem to be influenced - other things constant - by the expected prices of the generic substitute (Costa-Font, McGuire, \& Varol, 2014). As for parallel trade, a reduction of prices by approximately 4\% is estimated in the import market - relative to the prices of products not subject to parallel trade (Ganslandt \& Maskus, 2004). This evidence suggests how EU price regulation, even considering country differences, may have a beneficial effect on prices and citizens access to healthcare.

\section{Health Workforce and Patient Mobility}

Another important principle in the EU Internal Market is the free movement of people, which allows health professionals (e.g., doctors and nurses) to move cross-borders to take up employment in different countries. In addition, with the 2011 Directive of the European Parliament and the Council on cross-boarder patient mobility, citizens are also allowed to receive medical treatment in another Member State. However, evidence on the impact of free movement of 
individuals - both patients and health professionals - is still quite limited at the moment, both on quality of provided care, patient satisfaction as well as on overall system efficiency.

Available statistics show that the overall mobility of health professionals is relatively low, in line with the overall movement of citizens within the European Union (Ognyanova, Maier, Wismar, Girasek, \& Busse, 2012). However, it has been argued that for some Member States even losing a small number of health professionals may have adverse impacts in less developed regions. For these reasons, a careful coordination of the health workforces seems to be critical for the sustainability of health systems, given that many EU countries may face health workforce shortages in the near future.

To support EU Member States in facing these challenges, the EU has founded - within the second HP - a dedicated Joint Action on Health Workforce Planning and Forecasting. This Joint Action has been promoted with the specific aim of improving health workforce planning and forecasting across Europe, even if further investments should still be made to support countries in their planning efforts (Kroezen, Van Hoegaerden, \& Batenburg, 2018).

Regarding cross-border patient mobility, the Commission estimated a demand for cross-border healthcare close to $€ 10$ billion ( $1 \%$ of public healthcare spending in the EU) with around $50 \%$ of citizens interested in moving to a different Member States to receive care, according to the Eurobarometer.

However, even if there is an existing interest in cross-border healthcare patient mobility, official statistics keep showing that only a relative small number of citizens take advantage of this opportunity. In addition, a recent contribution in the literature argues that the impact of cross-boarder mobility on quality of care can be heterogenous among different EU regions (even counter-productive in some specific cases) with a specific reference to their level of economic development (Brekke, Levaggi, Siciliani, \& Straume, 2016). Further research is needed in this field to better understand the determinants of this mobility and its consequences. Also here the potential of learning 'what works' appears substantial.

\section{European Semester}

Healthcare financing in EU countries is mainly based on three sources: (1) funding from government revenues collected via taxation or social contributions; (2) funding from compulsory insurances schemes; (3) funding from some form of private sources provided by corporations, charities, out-of-pocket payments or voluntary health insurances intended to replace, complement or supplement the government coverage.

In 2016, around $77 \%$ of EU health spending was financed via government and compulsory insurances, see OECD \& European Union (2018), with governmental financing schemes mainly based on public transfers (coming from taxation and social insurance contributions paid by employees or their employers). Some variation still exists across Member States on the range of benefits covered and the extent of cost-sharing required - with still some room for better EU harmonisation (Schreyögg, Stargardt, Velasco-Garrido, \& Busse, 2005). 
Some European Semester CSRs suggested structural reforms aimed at improving fiscal sustainability by improving system efficiency. For example, some suggested the rebalancing of care from hospital towards primary care, prioritising of prevention and health behaviour, developing more integrated care (e.g., between healthcare and long-term care), ensuring cost-effective purchasing of pharmaceuticals, increasing efficiency of hospital (e.g., use of day care when appropriate, reduction of waiting times), benchmarking performances, workforce planning, effective budgeting governance and control (European Commission, 2016b).

To address the expected increase in healthcare demand associated with the ageing of population, actions were also implemented in the field of disease prevention and health promotion programmes (e.g., in Italy and France). In addition, recent healthcare reforms in the EU relate with the advancement of eHealth policies (e.g., in Germany and Austria among others) and of better performance monitoring of health systems through developing Health System Performance Assessment tools (see European Commission, 2016b).

Finally, CSRs also suggested to some governments ways to improve their financing-mix 'which allows for effective investment planning and continuity in organising and managing care delivery, thereby improving the resilience of the health system' (European Commission, 2014). To this end, a list of policy measures were suggested to improve the efficiency in the financing of the health systems, see European Commission (2016a); among these recommendations, it was suggested to

- reduce out-of-pocket payments;

- ensure universal coverage;

- adjust cost-sharing to promote efficiency.

CSRs on how to improve the financing-mix are usually tailored to the actual situation of each Member State; a comprehensive and robust evidence on their impact is still scarce and may not be easily generalised to other countries. Here the potential for learning 'what works' across EU borders appears sizable.

Azzopardi-Muscat, Clemens, Stoner, and Brand (2015) analyse the years 2011-2014 and show an increase in CSRs related to health, with a predominant focus on the policy objective of sustainability more than on social inclusion. One of the available strategies for EU countries in order to focus on long-term fiscal sustainability and cost-effectiveness of health systems while ensuring access to care, as stated in the European Social Charter, ${ }^{12}$ is the adjustment and re-design of costsharing policies for healthcare services and products.

Almost all Member States actually implement cost-sharing policies for some healthcare services, such as outpatient prescriptions, drugs, pharmaceuticals and dental care (Tambor et al., 2014). A cost sharing policy may generate additional sources of funding while improving efficiency in publicly financed healthcare systems via a reduction in the demand of unnecessary healthcare services (Zweifel \& Manning, 2000). However, a cost-sharing policy should also be carefully designed to minimise barriers to access for disadvantaged people, given that it may substantially contribute to the rising of health inequalities, as documented in the RAND Health Insurance Experiment and in some recent experiences from EU 
Member States (Berta, Levaggi, Martini, \& Verzillo, 2017; Guthmuller, Jusot, \& Wittwer, 2014; Guthmuller \& Wittwer, 2017; Newhouse et al., 1993).

In practice, this means re-designing cost-sharing policies at Member States level ensuring exemptions for both disadvantaged people and chronic patients or valuebased cost-sharing policies (Tambor, Pavlova, Golinowska, \& Groot, 2015). With careful design, cost sharing policies can effectively be used to ensure value for money and the sustainability of the healthcare systems. Again cross-border learning on this appears a promising source of positive externalities of EU actions.

\section{Potential for Externalities}

As presented in the previous sections, a growing number of tools (through grants for collaborative projects, joint actions, expert group meetings, etc.) that are basis for knowledge and experience sharing among Member States have been recently implemented to improve efficiency and quality of national healthcare systems (European Commission, 2019). This subsection gives an overview of existing collaborative actions where EU produces positive externalities; it also claims that EU health policies could further gain from enhanced collaboration among Member States.

\section{Collaboration among Member States}

European Reference Networks on rare and complex diseases provide key knowledge and resource-sharing among patients and health providers across Europe (European Commission, 2018a). Recent examples of cross-border collaboration showed also for instance, how cooperation between Member States improves access to healthcare to patients, via common investment in expensive medical devices (European Commission, 2016a).

Another example of EU cross boarder collaboration is in blood, tissues, cells and organs donations. The 2010 European Organs Directive sets the safety and quality requirements to ensure donors and recipients are guaranteed the same quality, safety and legal standards across Europe (European Parliament and Council, 2010). An action plan strengthens cooperation among Member States to tackle the insufficiency of available human organs and the shortage of donors (European Parliament, 2010). In this regard, the creation and the maintenance of national and European donors' registries for living donations is essential to harmonise the health and safety of living donors to evaluate and monitor the practice of donation in the European Union and to fight organ trafficking.

Cooperation at EU level is also justified for other public health interventions, such as vaccination programmes. The recommendation from the Council (2018) and the opinion from the Expert Panel on effective ways of investing in Health (European Commission, 2018b; Siciliani et al., 2020) calls for more cooperation across Member States to tackle the recent decrease of confidence in vaccination, and the following increase in outbreaks of vaccine-preventable diseases.

In addition, 'the Commission strongly encourages cooperation between Member States on eHealth, and supports them in developing and implementing cost-effective and interoperable eHealth solutions to improve health systems'. ${ }^{13}$ With Directive 
2011/24, the Commission supports the eHealth network and the 2012-2020 eHealth Action Plan, with the aim of improving interoperability and standardisation for the cross-border exchange of access to data. Moreover, the Commission promotes digitalisation of public health infrastructures, in line with the current 'Digital Europe Agenda'. ${ }^{14}$ These include telemedicine services, as stated by the EC Communication on 'Effective, accessible and resilient health systems', see European Commission (2014).

\section{Health Information for Evidence-based Policy}

All these collaborative efforts involve sharing access to health data, at high granularity and quality, to perform research on the effectiveness both of cure pathways as well as on sustainability-related measures.

In this light, the evidence available on EU actions described above, while already significant, could be greatly expanded to the benefit of EU citizens. An enhanced access to EU wide health data to measure 'what works best' in EU actions would bring benefits at limited extra cost.

There are several examples of learning across borders; for instance, Stadhouders, Kruse, Tanke, Koolman, and Jeurissen (2019) map available evidences from OECD countries on how cost-containment policies have been effective or not in containing healthcare costs. Here cost-containment policies are defined in a counterfactual fashion as policies aimed at lowering total expenditure with respect to a proper control group before and after the implementation of the intervention. The paper shows that, unfortunately, many widely adopted policies are supported by limited evidence on their effectiveness in containing healthcare costs.

Restricting attention only to the high-quality evidence, the paper suggests how a combination of cost sharing, managed care competition, reference pricing and generic substitution may be effective in containing the cost curve. Often the effects are strongly context-dependent, which implies that - as always - policies need to be tailored to each Member State's specific reality. However, there appears to be large room for EU countries to learn from each other's experiences, both on efficiency and effectiveness of the implemented policies.

A wide range of data sources could be used for research and the evaluation of EU actions, available at Member States and/or EU level. ${ }^{15}$ The eHealth plan, for example, aimes also at enabling the use of medical data for public health research, potentially providing a relevant contribution to ensure sustainability of the healthcare systems.

Another source of information may come from sharing life-course data on patients across EU borders, as patients mobility increase within the EU. The working of EU society provides a wealth of data, affected by many factors related to different urbanisation levels, environmental conditions, medical practice, cure pathways, financial co-payment incentives. These data has the potential to unveil what works for which type of disease, given people's age and personal health conditions. In this sense, the EU appears to offer many natural or quasiexperiments to learn from. 
The potential of pooling of data has a strong justification, for instance, for rare forms of disease: each Member State would not have enough patient records to warrant a precise statistical analysis, and pooling data across Member States could build large-enough data bases for a proper analysis. Beyond the case of rare diseases, access to similar data across borders would permit to validate domestic results, perform cross-tests and formulate more refined hypothesis on how to optimise cure pathway or policies that work best for the specific characteristics of each patient, including pre-existing health conditions.

Data-sharing hence appears critical to unlock the potential for additional positive externalities of learning what works, both for finding cures and for making health systems more sustainable.

\section{FUTURE EU ACTIONS ON HEALTH}

This section looks at future actions for strengthening the responsiveness and sustainability of healthcare systems.

\section{Cancer Plan}

Cancer is one of the first causes of death in the EU for people aged 45-64 in a growing number of EU countries. It is likely to remain one of the biggest killers in the twenty-first century. Cancer has been designated as a mission area in the preparation of Horizon Europe, the next research and innovation funding programme.

In this context, EC President's Ursula Von der Leyen has tasked Stella Kyriakides, European Commissioner for Health and Food Safety, with the launch of an ambitious Cancer Plan. Europe's Cancer Plan is going to propose actions at every key stage of the disease: prevention (lifestyle, pollution, vaccination), diagnosis, treatment and survivorship. This common research effort makes sense to avoid duplication of costs, and to attain economies of scale, with a more efficient allocation of tasks, pooling of evidence and results dissemination efforts.

A new EC Knowledge Centre on Cancer (hosted at the Joint Research Centre) was endorsed on 5 February 2020 by Commissioner Marija Gabriel to foster Scientific and Technical coordination of EC cancer-related activities, especially between the new Horizon Europe Mission on Cancer $^{16}$ and the new Europe's Beating Cancer Plan. ${ }^{17}$ This Knowledge Centre will serve as evidence-clearing house for policy making on prevention, early detection, treatment and survivorship, assessing new evidence for its robustness to serve as a base for new policies. It will manage the EU Cancer Information System and develop guidelines and quality assurance schemes on cancer. It aims to provide a data hub/platform for cancer, serving as an 'honest data broker' to access data via the European Health Data Space, linking up with different (research) infrastructures and to work on standardising data collection and exchanges. 


\section{Pharmaceutical Roadmap}

A second future EU priority is expected to address EU's pharma supply, its affordability, both for citizens and for taxpayers, taking also innovation into account. This will help ensure Europe's supply of safe and affordable medicines, and to support the European pharmaceutical industry's innovation efforts in the EU.

To address the issue of medical innovation and competitiveness, the Commission has laid out three key priorities: maintaining and increasing European pharma's competitiveness both inside and outside Europe, turning climateneutral by 2050 and improving the digital business environment. Again here there appears to be a vast potential to use the positive externalities of 'learning what works'.

\section{Challenges from the COVID-19}

The COVID-19 pandemic has hit the EU in the spring of 2020. This has highlighted the need for increased cooperation on disease containment, both worldwide and within the EU. It has also impacted EU's economies at large, including their ability to sustain their healthcare systems.

Part of the response to the pandemic involves investment in the health sector. The Commission has launched the 'Coronavirus Global Response' on 4 May 2020, a funding drive to develop a COVID-19 vaccine, with a goal to raise $€ 4$ billion to research vaccines, $€ 2$ billion for treatments and $€ 1.5$ billion to develop testing kits. ${ }^{18}$ It has also mobilised $€ 2.7$ billion through the EU Emergency Support Instrument for the healthcare sector accompanied by $€ 300$ million through the EU medical equipment capacity. This funding is aimed at helping Member States with urgent needs in the framework of fighting against COVID-19 such as purchasing and distribution of masks and respirators, setting up of field hospitals, boosting the development of medication and testing methods and supporting and coordinating the transport of medical equipment and patients in cross-border regions.

A complementary part is the Recovery plan for Europe, ${ }^{19}$ a proposed action for the long-term EU recovery and kick-starting European economies, mitigating the social damage caused by the coronavirus pandemic.

Beyond funding, there is high potential to have positive externalities to the COVID-19 response from learning from experience. The pandemic has shown the need to better harvest and use timely information. Learning what health measures work under what circumstances is ever more needed in this context, even beyond the sustainability of Member States healthcare systems per se.

Times of crisis are an occasion to learn, but making lessons learnt permanent is not easy. Dr Julie Gerberding, Head of the Centre for Disease Control in the US in 2003 during the SARS crisis, recently wrote:

We have an outbreak and we react to it. (...) But then when the threat goes away, so does the investment, engagement and attention. And we go back into a false sense of security and complacency until the next one comes (TIME, 2020). 
The COVD-19 response could benefit from more learning across Member States, in line with the subsidiarity principle. The EU needs to tackle diseases that see no borders, while keeping EU policy within its complementary supporting role with respect to health policies of Member States. 'Learning what works' for mitigating the epidemic can be achieved by opening up safe data-access to the rest of the European Union.

As recently suggested by Klaus Schwab of the World Economic Forum and Guido Vanham, Prof. of Virology at the University of Antwerp

...which aspects [for releasing lockdowns] they start first (...) should be a country-by-country choice. But once best practices become clear, countries should be willing to learn and coordinate with one another (TIME, 2020).

Some risk factors challenging the responsiveness of the healthcare systems were exacerbated by lockdown measures associated with COVID-19, such as mental health risks and limitation to healthy physical activity. Above all, however, an economic crisis is now looming over the global economy, as an immediate consequence of COVID-19-related lockdowns. For COVID-19, Schwab and Vanham predict it is likely to be a matter of several years before a drug and vaccine are brought to the market. They suggest that

if we want to come out of this (COVID-19) unscathed in the long run, we must plan for unprecedented impact and collaboration in the short run.

\section{CONCLUDING REMARKS}

The EU relies on regulation as its key policy tool, with limited recourse to direct expenditure. This implies that EU actions often take the form of providing guidelines and norms, and facilitating networks rather than by actively financing activities. The potential to generate value added in this way appears large, especially for 'learning what works' through sharing access to data across EU borders. This area could bring vast amount of needed knowledge on best medical treatment, as well as on the most sustainable health policies from the cost side.

This, however, requires Member States and EU institutions to raise the level of collaboration and coordination. At the present time of the COVID-19 crisis, this seems as needed as ever. When looking forward to the time after the COVID-19 crisis, Michail Gorbachev recently stated:

The world will never be the same. But what it will be like? That depends on what lessons will be learned (TIME, 2020).

The European Union could learn more together.

\section{NOTES}

1. The principle of subsidiarity is defined in Article 5 of the Treaty on European Union; see https://eur-lex.europa.eu/summary/glossary/subsidiarity.html.

2. Sustainable Development Goal 3: Ensure healthy lives and promote well-being for all at all ages. 
3. See https://ec.europa.eu/info/business-economy-euro/economic-and-fiscal-policy-coordination/eu-economic-governance-monitoring-prevention-correction/stability-and-growthpact_en.

4. See https://ec.europa.eu/info/business-economy-euro/economic-and-fiscal-policy-coordination/eu-economic-governance-monitoring-prevention-correction/european-semester_en.

5. The authors reported that these estimates are obtained mainly using data provided by the Organisation for Economic Cooperation and Development (OECD), the World Health Organisation (WHO) integrated with country specific estimates of the ratio of health expenditure on cancer care with respect to the total.

6. The European Code Against Cancer - an EU initiative - aims at informing people on the actions they can personally take to reduce their own risk of cancer (see The European Code Against Cancer).

7. https://healthcare-quality.jrc.ec.europa.eu/.

8. https://ec.europa.eu/jrc/en/publication/brochures-leaflets/ecicc-european-commissioninitiative-colorectal-cancer.

9. https://ecis.jrc.ec.europa.eu/.

10. Established by Regulation (EU) No 282/2014.

11. The Organisation of European Cancer Institutes (OECI) is an EU association pursuing the mission of helping the development of EU comprehensive cancer centres by fostering the integration between care and cancer prevention with cancer research and education.

12. Revised European Social Charter, Strasbourg 3 May 1996.

13. $\operatorname{COM}(2012) 736$.

14. https://ec.europa.eu/digital-single-market/en/europe-investing-digital-digital-europeprogramme.

15. Respecting the requirements on data protection provided by the GDPR.

16. https://ec.europa.eu/info/horizon-europe-next-research-and-innovation-frameworkprogramme/mission-area-cancer_en.

17. https://ec.europa.eu/info/law/better-regulation/have-your-say/initiatives/12154-Europes-Beating-Cancer-Plan.

18. see https://europa.eu/global-response/.

19. https://ec.europa.eu/info/live-work-travel-eu/health/coronavirus-response/recoveryplan-europe_en.

\section{REFERENCES}

Azzopardi-Muscat, N., Clemens, T., Stoner, D., \& Brand, H. (2015). EU country specific recommendations for health systems in the European Semester process: Trends, discourse and predictors. Health Policy, 119(3), 375-383. doi:10.1016/j.healthpol.2015.01.007

Bayntun, C. (2012). A health system approach to all-hazards disaster management: A systematic review. PLoS Currents, 4. doi:10.1371/50081cad5861d.

Berta, P., Levaggi, R., Martini, G., \& Verzillo, S. (2017). The redistributive effects of copayment in outpatient prescriptions: Evidence from Lombardy. BMC Health Services Research, 17(336). doi:10.1186/s12913-017-2248-6.

Brekke, K. R., Levaggi, R., Siciliani, L., \& Straume, O. R. (2016). Patient mobility and health care quality when regions and patients differ in income. Journal of Health Economics, 50, 372-387. doi:10.1016/j.jhealeco.2016.05.003.

Carrieri, V., \& Wuebker, A. (2016). Quasi-experimental evidence on the effects of health information on preventive behaviour in Europe. Oxford Bulletin of Economics \& Statistics, 78(6), 765-791. doi:10.1111/obes.12134.

Costa-Font, J., McGuire, A., \& Varol, N. (2014). Price regulation and relative delays in generic drug adoption. Journal of Health Economics, 38, 1-9. doi:10.1016/j.jhealeco.2014.04.004.

Council. (2003). Council Recommendation of 2 December 2003 on cancer screening. Official Journal of the European Union. L 327/34.

Council. (2018). Council Recommendation of 7 December 2018 on strengthened cooperation against vaccine preventable diseases. Official Journal of the European Union. 2018/C 466/01. 
Crato, N., \& Paruolo, P. (Eds.). (2019). Data-driven policy impact evaluation: How access to microdata is transforming policy design. (1st ed.). Zurich CH: Springer International Publishing. doi:10.1007/ 978-3-319-78461-8.

European Commission. (2007). WHITE paper together for health: A strategic approach for the EU 2008-2013. Official Journal of the European Union. COM(2007) 630 final.

European Commission. (2009). Pharmaceutical sector inquiry final. Final Report. Retrieved from https:// ec.europa.eu/competition/sectors/pharmaceuticals/inquiry/staff_working_paper_part1.pdf.

European Commission. (2013). Identifying fiscal sustainability challenges in the areas of pension, health care and long-term care policies. doi:10.2765/85081.

European Commission. (2014). Communication from the Commission: On effective, accessible and resilient health systems. COM(2014)0215 final.

European Commission. (2016a). Study on better cross-border cooperation for high-cost capital investments in health. Final Report. doi:10.2875/36129.

European Commission. (2016b). Joint report on health care and long-term care systems \& fiscal sustainability. European Economy Institutional Papers, 1(37). doi:10.2765/680422.

European Commission. (2017). Mid-term evaluation of the 3rd health programme 2014-2020 under regulation (EU) No 282/2014 on the establishment of a third programme of union action in the field of health (2014-2020). COM(2017) 586 final.

European Commission. (2018a). Application of the ERN model in European cross-border healthcare cooperation outside the rare diseases area. Opinion from the Expert Panel on effective ways of investing in Health (EXPH). doi:10.2875/562372.

European Commission. (2018b). Vaccination Programmes and Health Systems in the European Union. Report by the Expert Panel on effective ways of investing in Health (EXPH). doi:10.2875/18503.

European Commission. (2018c). Communication on enabling the digital transformation of health and care in the Digital Single Market; empowering citizens and building a healthier society. Communication. COM/2018/233 final.

European Commission. (2019). Tools and methodologies to assess the efficiency of health care services in Europe. Report by the Expert Group on Health System Performance Assessment. doi:10.2875/ 346480.

European Council. (2006). Council conclusions on common values and principles in European Union health systems. Official Journal of the European Union. C 146.

European Council. (2011). Council conclusions: Towards modern, responsive and sustainable health systems. Official Journal of the European Union. C 202.

European Council. (2013). Council conclusions on the reflection process on modern, responsive and sustainable health systems. Retrieved from https://www.consilium.europa.eu/uedocs/cms_data/ docs/pressdata/en/lsa/140004.pdf.

European Parliament. (2010). Resolution of 19 May 2010 on the Commission communication: Action plan on organ donation and transplantation (2009-2015): Strengthened cooperation between member states (2009/2104(INI)). Official Journal of the European Union. 2011/C 161 E/11.

European Parliament and Council. (2002). Decision No 1786/2002/EC of 23 September 2002 adopting a programme of Community action in the field of public health (2003-2008). Official Journal of the European Communities. L 271.

European Parliament and Council. (2007). Decision No 1350/2007/EC Establishing a second programme of Community action in the field of health (2008-13). Official Journal of the European Union. L 301 .

European Parliament and Council. (2010). Directive 2010/45/EU on standards of quality and safety of human organs intended for transplantation. Official Journal of the European Union. L0053.

European Parliament and Council. (2011). Directive 2011/24/EU on the application of patients' rights in cross-border healthcare. Official Journal of the European Union. L 88.

European Parliament and Council. (2014). Regulation (EU) No 282/2014 on the establishment of a third programme for the Union's action in the field of health (2014-2020). Official Journal of the European Union. L 086.

European Parliament and Council. (2015). Regulation (EU) 2015/1017 on the European Fund for Strategic Investments, the European Investment Advisory Hub and the European Investment Project Portal. Official Journal of the European Union. L 169. 
European Pillar of Social Rights. (2017). The European pillar of social rights in 20 principles. doi:10.2792/ 95934.

Ganslandt, M., \& Maskus, K. E. (2004). Parallel imports and the pricing of pharmaceutical products: Evidence from the European Union. Journal of Health Economics, 23(5), 1035-1057. doi:10.1016/j.jhealeco.2004.03.005.

Greer, S. L., Fahy, N., Rozenblum, S., Jarman, H., Palm, W., Elliott, H. A., \& Wisma, M. (Eds.). (2019). Everything you always wanted to know about European Union health policies but were afraid to ask. Health Policy Series. Geneva: WHO. ISBN 9789289051767.

Guthmuller, S., Jusot, F., \& Wittwer, J. (2014). Improving takeup of health insurance program a social experiment in France. Journal of Human Resources, 49(1), 167-194. doi:10.3368/jhr.49.1.167.

Guthmuller, S., \& Wittwer, J. (2017). The impact of the eligibility threshold of a French means-tested health insurance programme on doctor visits: A regression discontinuity analysis. Health Economics, 26(12), e17-e34. doi:10.1002/hec.3464.

Hofmarcher, T., Lindgren, P., Wilking, N., \& Jönsson, B. (2020). The cost of cancer in Europe 2018. European Journal of Cancer, 129, 41-49. doi:10.1016/j.ejca.2020.01.011.

Kroezen, M., Van Hoegaerden, M., \& Batenburg, R. (2018). The joint action on health workforce planning and forecasting: Results of a European programme to improve health workforce policies. Health Policy, 122(2), 87-93. doi:10.1016/j.healthpol.2017.12.002.

Kruk, M. E., Myers, M., Varpilah, S. T., \& Dahn, B. T. (2015). What is a resilient health system? Lessons from Ebola. The Lancet, 385(9980). 1910-1912. doi:10.1016/S0140-6736(15)60755-3.

Legido-Quigley, H., Glinos, I. A., Baeten, R., McKee, M., \& Busse, R. (2012). Analysing arrangements for cross-border mobility of patients in the European Union: A proposal for a framework. Health Policy, 108(1), 27-36. doi:10.1016/j.healthpol.2012.07.001

Newhouse, J. P., \& the Rand Insurance Experiment Group. (1993). Free for all?: Lessons from the Rand Health Insurance Experiment. Cambridge, MA: Harvard University Press. doi:10.7249/CB199.

OECD, \& European Union. (2018). Health at a glance: Europe 2018. doi:10.1787/health_glance_eur2018-en.

Ognyanova, D., Maier, C. B., Wismar, M., Girasek, E., \& Busse, R. (2012). Mobility of health professionals pre and post 2004 and 2007 EU enlargements: Evidence from the EU project prometheus. Health Policy, 108(2-3), 122-132. doi:10.1016/j.healthpol.2012.10.006.

Reillon, V. (2015). EU framework programme for research and innovation: Evolution and key data from FP1 to Horizon 2020 in view of FP9. European Parliament- EPRS PE. 608.697. doi:10.2861/ 60724.

Ringborg, U., Pierotti, M., Guy, S., \& Tursz, T. (2008). Managing cancer in the EU: The organisation of European cancer Institutes (OECI). European Journal of Cancer, 44(6), 772-773. doi: 10.1016/j.ejca.2008.01.012.

Schopper, D., \& Wolf, C. de (2009). How effective are breast cancer screening programmes by mammography? Review of the current evidence. European Journal of Cancer, 45(11), 1916-1923. doi:10.1016/j.ejca.2009.03.022.

Schreyögg, J., Stargardt, T., Velasco-Garrido, M., \& Busse, R. (2005). Defining the 'health benefit basket' in nine European countries. The European Journal of Health Economics, 6(1), 2-10. doi:10.1007/ s10198-005-0312-3.

Siciliani, L., Wild, C., McKee, M., Kringos, D., Barry, M. M., Barros, P. P., ... Ricciardi, W. (2020). Strengthening vaccination programmes and health systems in the European Union: A framework for action. Health Policy. 124(5), 511-518. doi:10.1016/j.healthpol.2020.02.015.

Stadhouders, N., Kruse, F., Tanke, M., Koolman, X., \& Jeurissen, P. (2019). Effective healthcare costcontainment policies: A systematic review. Health Policy, 123(1), 71-79. doi:10.1016/ j.healthpol.2018.10.015.

Tambor, M., Pavlova, M., Golinowska, S., \& Groot, W. (2015). Can European countries improve sustainability of health care financing through patient cost-sharing? Frontiers in Public Health, 3, 196. doi:10.3389/fpubh.2015.00196.

Tambor, M., Pavlova, M., Rechel, B., Golinowska, S., Sowada, C., \& Groot, W. (2014). The inability to pay for health services in Central and Eastern Europe: Evidence from six countries. The European Journal of Public Health, 24(3), 378-385. doi:10.1093/eurpub/ckt118. 
Tarricone, R., Torbica, A., \& Drummond, M. (2017). Challenges in the assessment of medical devices: The Medtechta project. Health Economics, 26, 5-12. doi:10.1002/hec.3469.

TIME. (2020, April 27). Finding hope. A TIME 100 special report. Time Magazine, 195(15).

Watson, J. (2016). Health and structural funds in 2007-2013: Country and regional assessment. European Commission DG SANTE. Retrieved from https:/ec.europa.eu/health/sites/health/ files/health_structural_funds/docs/watson_report.pdf.

Wouters, O. J., Kanavos, P. G., \& McKee, M. (2017). Comparing generic drug markets in Europe and the United States: Prices, volumes, and spending. The Milbank Quarterly, 95(3), 554-601. doi:10.1111/1468-0009.12279.

Zweifel, P., \& Manning, W. G. (2000). Moral hazard and consumer incentives in health care. Handbook of Health Economics (Vol. 1, pp. 409-459). Amsterdam: Elsevier. doi:10.1016/S1574-0064(00) 80167-5. 